\title{
Technology Preparedness and the Impact on a High-Quality Remote Learning Experience: Lessons From COVID-19
}

\author{
Frances M. Hawes \\ University of Wisconsin Eau Claire \\ Michael E. Marrapodi \\ Cambridge College \\ Amanda Colligan \\ Quincy College
}

\begin{abstract}
The COVID-19 crisis has highlighted the role of remote learning in higher education. Increased investments and understanding of the transition to remote learning today will yield access to high-quality learning. Using data from an institution with a diverse student population, the purpose of this study was to explore students' transition to remote learning during the COVID-19 pandemic by examining aspects within the course that contributed to perceptions of a high-quality remote learning experience. Five elements of the remote learning experience were statistically significant predictors of course quality ratings: ratings of the quality of student supports (Academic Advising, Tutoring, Internships, Financial Aid, etc.), ratings of connectedness to instructors in at least one class, the use of many learning activities by instructors, clear course organization by instructors, and clear communication used by instructors. Analysis of qualitative student interviews reinforced these findings and provided further support for the importance of reliable technology during remote learning.
\end{abstract}

Keywords: Covid-19, diverse student population, high quality learning, remote instruction, technology preparedness

\section{INTRODUCTION}

As a result of the COVID-19 pandemic, over 1.2 billion students are out of the classroom (World Economic Forum, 2020). This has forced most learners to move to online education for the indefinite future. There is evidence that some students may be more successful in a face-to-face format compared to online (Peterson \& Bond, 2004; Figlio et al., 2010), resulting in concerns for student success. Some research suggests that certain types of students may be at a disadvantage in their abilities to adjust to online courses, including younger, male, and Black students (Xu \& Jaggars 2013; Dumford \& Miller, 2018). Compounding these anxieties is the abrupt transition from traditional face-to-face classrooms to remote learning, which is not equivalent to traditional online learning. 
It is pertinent to distinguish the difference between remote learning and online learning. With remote learning, teaching that would normally take place in a classroom is instead conducted remotely, using video conferencing tools (such as Google Meet and Zoom) in conjunction with the institution's learning management system. Online learning, on the other hand, occurs when a course has been developed with support from an instructional designer (often over weeks or months) with the intention for fully online delivery (Hodges et al., 2020). With the growth of learning remotely, more attention to the quality of online higher education is paramount. Furthermore, the rapid rise in remote learning presents the need for a better understanding about how well these programs work with diverse learners in higher education. Using data from an institution with a diverse student population, the purpose of this paper is to consider the readiness of college students for remote learning and to suggest issues that need to be addressed to maximize the opportunities and minimize the drawbacks associated with remote learning and technology access.

\section{LITERATURE REVIEW}

\section{Quality in Online Learning}

As the demands for remote learning within higher education increase, institutions must evaluate quality within these educational programs. This study is important because it measures the level of quality and the level of satisfaction among students as highlighted by Parasuraman et al., (1985). Their research focused on service quality from the consumer's standpoint and the importance of satisfaction of consumers in relation to quality. A significant amount of research has since focused on satisfaction and quality in various service settings, including higher education. The ServQual or Gap models outline that satisfaction is based on how well a service level aligns with customer expectations (Parasuraman et al., 1985; Letcher \& Neves, 2010).

Full reviews of SERVQUAL and student satisfaction research are outside the scope of this paper. Based on the previous studies that have been mentioned, this research examines student satisfaction and perceived quality factors in online education. While quality may be challenging to quantify, there have been several benchmarks that are considered essential for ensuring quality learning in online education; student supports (Milman et al., 2015), faculty support (Boling et al., 2012), course development (Dumford \& Miller, 2018), and course structure (Hew \& Cheung, 2008).

\section{Student Support}

A report by Allen and Seaman (2014) emphasized the importance of establishing effective student support systems to help online learners. Student support is commonly offered by colleges and includes advising, tutoring, and learning management systems, to name a few. Research by Milman and colleagues (2015) investigated the satisfaction with administrative, academic, technical, and online community supports of first and second year online graduate master's students. It was found that the percent of students who were satisfied or very satisfied with student support services varied. Furthermore, students reported varying levels of importance among support services, with higher percentages of students reporting importance of the registrar and admissions offices compared with career services, writing center, international student, veteran's services, and the counseling center.

\section{Faculty Support}

For online learning to be successful, guidance from and interaction with the instructor are required, as the instructor plays a large role in establishing a sense of community (Desai et al., 2009; Boling et al., 2012). Gray \& DiLoreto (2016) examined the effects of social presence, in the form of speed of instructor response, and found that it strongly impacted student satisfaction. Timely, transparent communication with the instructor plays a central role in influencing student satisfaction. Along with rapid communication, behaviors such as encouraging involvement, and offering individual feedback can be beneficial for students (Hackman \& Walker, 1990; Gallien \& Oomen- Early, 2008). 


\section{Course Development \& Structure}

Other critical elements to quality online learning include course development and structure. Online classrooms provide a multitude of tools used to facilitate communication between instructors and students and facilitate student-to-student communication as well as learner- content interaction (Hew \& Cheung, 2008). Online coursework has the potential to create a high-quality learning environment where students can actively engage with material (Johnston et al., 2005; Smart \& Cappell, 2006). Findings are mixed, however, on what tools are most beneficial to a high-quality learning experience. For example, there have been many studies that show the positive impact on learning with the use of online discussion boards (Rettig, 2013); however, research by Lee (2014) found that discussion board use was less significant to make online learning satisfactory. Furthermore, some students conveyed that Zoom is an effective form of learning; whereas other students perceived it as having a negative effect on their learning experience and their motivation to learn (Seaman et al., 2018).

\section{Technology Preparedness and the Impact on Quality}

Given the abrupt transition to remote learning during COVID-19, this research will further examine the strength and barriers to computer technology integration. As educational institutions shift to remote learning for the indefinite future, it is important to examine if students and institutions are prepared to engage successfully in this format. The assumption that students have reliable access to devices and are technologically literate because they are exposed to technology at an earlier age is incorrect, or rather, incomplete. Several studies have highlighted that students' online learning experience may be less effective due to the difficulty of access to technical assistance (Gray \& DiLoreto, 2016).

\section{Technology Access}

First and foremost, a reliable device with access to the Internet is required for any online learning. Students without dependable access to the Internet and/or appropriate technology may struggle to participate in remote learning. This results in a digital divide between college students who can access the required resources and those who cannot (Hall et al., 2020). As reported by the Federal Communications Commission in 2019, about 21 million Americans lacked broadband access. These numbers are compounded by geographical location and socio-economic background (Harris et al., 2017; Anderson, 2018). The degree of home access to computers by diverse demographic groups in the U.S. has been documented through reports issued by the National Telecommunications and Information Administration. The most recent data, collected in 2016, show that "non-Asian minorities and people with disabilities were among those groups most likely not to use the Internet at home" (NTIA, 2016, p. 1). Students who rely on technology available on their college campus may now be left with challenges that could impede their ability to succeed as campus access has been restricted or eliminated.

\section{Technology Skills}

Engaging in the remote learning process requires specific computer and web technology skills (Lee \& Witta, 2001). Research by Stokes (2003) sampled undergraduate students enrolled in two web-based instructional modules during the Spring 2001 semester at The University of Alabama and found a significant relationship between the level of comfort when using online tools and student satisfaction. Other research confirms these findings and illustrates that if frustrated with technology, students may express lower satisfaction (Hara \& Kling, 2001; Alqurashi, 2019). Many college instructors assume traditional college students are "technology savvy" however, there is research that highlights concerns regarding student computer skills and technology knowledge (Hew \& Brush, 2007). For example, Ku et al. (2020) reported findings of 21 graduate students and found that they felt less satisfied with online learning because they lacked the skills to use the technology.

A wide range of strategies and technologies to support student success during COVID-19 are available and may prove instrumental in assisting students to adapt to remote learning (Grajek \& Brooks, 2020). Tools such as Zoom, Google Meet, MicrosoftTeams, and others, intend to facilitate various learning 
modalities, which in turn supplement the students' learning experiences. However, students' satisfaction rests on the foundation of their ability to access and understand these online learning tools.

\section{Contributions of This Research}

Prior research on online learning shows that student satisfaction is critical to achieving the course learning outcomes and the success of online implementation (Sun et al., 2008; Ke \& Kwak, 2013). With the sudden shift away from the physical classroom, the perceptions of college learners towards the transition to remote learning during COVID -19 is essential to better understand the relationship between technology preparedness and student satisfaction. This mixed -methods study intends to gain further insight into the challenges faced by students in higher education during the COVID-19 pandemic and the impact of these challenges on student satisfaction. The focus of this paper is the identification of variables that may impact the quality of learning with the transition to remote learning experiences. These variables could be considered during remote course instructional design and instruction to promote high quality remote learning.

Using an explanatory sequential mixed method design, the research questions for this study are as follows:

Research Question 1: What factors do students perceive as contributing to a high-quality learning experience during the remote learning transition?

Research Question 2: What is the relationship between technology preparedness and overall ratings of high-quality learning?

Research Question 3: What are students' lived experiences with technology and high-quality learning in a remote learning modality during the summer 2020 term?

\section{METHODS}

\section{Context}

The research was completed in the summer of 2020 during the COVID-19 pandemic. The College moved all on-campus, in seat instruction to a remote format in March 2020. The summer term, which began in June, continued in the remote modality.

A student survey was created to elicit the following information:

1) Student ratings of course quality, instructional support, and services during the summer term.

2) Student technology challenges.

\section{Design}

A sequential explanatory mixed methods approach was selected for the study as the most suitable to answer the research questions (Ivankova et al., 2006). First, the quantitative data was collected and analyzed using both descriptive and inferential statistics. Then the qualitative research was conducted using a phenomenological approach. By using this sequence, the survey responses could be reviewed and analyzed, and this analysis informed the creation of the instrument used for the interview protocol.

\section{Participants}

The survey was sent to 1,706 students who registered for courses during the summer 2020 term. The survey had a $31 \%$ response rate (529 responses). Of these respondents, $25 \%$ were enrolled in the undergraduate program, $32 \%$ in the graduate programs in education, $13 \%$ in the graduate programs in business, and $30 \%$ in the graduate programs in counseling and psychology. A total of 288 students were enrolled at the main campus and 241 students were enrolled at one of the 4 regional centers. Students from all 5 locations participated in the study. 
On average, students were enrolled in at least 2 classes during the summer term. Classes were offered in three modalities, remote only (using Zoom), hybrid (using Zoom and the learning management system), and online (using the learning management system only, no Zoom sessions). Two hundred sixty-five students $(50 \%)$ reported enrolling in hybrid courses, while $154(29 \%)$ enrolled in remote (Zoom only) courses, $88(29 \%)$ enrolled in a combination of modalities, and 22 enrolled in online only courses.

Two hundred thirteen students (40\%) identified as Hispanic or Latino, $130(25 \%)$ identified as White, 109 (21\%) identified as Black or African-American, 16 (3\%) as Asian, 14 as multi-racial (3\%) and 47 (9\%) did not declare a race or ethnicity. Four hundred two students (76\%) identified as women, while 87 students $(16 \%)$ identified as men, and less than $1 \%$ identified as non-binary. Thirty-seven students (7\%) did not identify a gender. Demographics of those who responded to the survey are similar to overall College demographics, though there is a significant over-representation of graduate students among respondents when compared to the overall student body.

The 529 students who completed the survey were contacted via email and invited to participate in a one-on-one interview. Sixteen (16) students replied to this email and expressed interest in the interview process. All 16 were sent the informed consent document and 12 agreed to be interviewed by one of the researchers. Zoom sessions were set up with these students and 10 ultimately completed the interview process. The informed consent document was reviewed at the beginning of each Zoom session and the student's consent was recorded, as was the remainder of the interview.

\section{Survey}

The Institutional Research Office of the college from which data was collected authorized the student survey. The questions and response choices were vetted and revised in consultation with appropriate administrators. The survey was released through SurveyMonkey and was in the field for approximately two weeks. The researchers authored the interview questions after a review of extant literature and the results of the quantitative analysis. The interview protocol was influenced by the COVID-19 pandemic, which resulted in the interviews being conducted via Zoom rather than in person.

\section{RESULTS}

After meeting all conditions for conducting a regression model, the data were analyzed using hierarchical regression analysis to assess the ability to predict overall quality of remote instruction during the Summer 2020 term. In the first step, characteristics of the student and the courses (race, gender, the remote instruction modality, and the number of courses enrolled) were kept under control. In the second step, independent variables were added to understand the connectedness of students to their professors and student supports. Finally, variables were added to look at specific online classroom practices that predicted course quality (classroom clarity, course organization, and the use of many activities). Control variables in model 1 only explained $1.3 \%$ of the variation in ratings of quality of online instruction. Model 2 saw significant improvements when adding in variables that spoke to the connection of students to their professors and to student support services. These variables, when controlling for demographics, course modality, and the number of courses, explained $34.6 \%$ of the variation in quality ratings of online instruction. 
TABLE 1

HIERARCHICAL REGRESSION ANALYSIS OF PREDICTORS OF QUALITY OF REMOTE INSTRUCTION

\begin{tabular}{|c|c|c|c|}
\hline Predictor Variables & $\begin{array}{l}\text { Regression } 1 \text { - } \\
\text { Controls } \\
\beta \\
\end{array}$ & $\begin{array}{l}\text { Regression } 2- \\
\text { Connection to Professor } \\
\text { and Student Services } \\
\beta\end{array}$ & $\begin{array}{l}\text { Regression } 3 \text { - } \\
\text { Professor Engagement } \\
\text { Strategies } \\
\beta\end{array}$ \\
\hline Race & $-.079^{*}$ & $-.078^{*}$ & -.036 \\
\hline Gender & .003 & .006 & .015 \\
\hline Modality & .004 & -.014 & -.035 \\
\hline Number of Courses & -.058 & -.038 & -.025 \\
\hline Have Reliable Internet & .040 & -.008 & -.007 \\
\hline $\begin{array}{l}\text { Average Rating of Quality } \\
\text { of All Student Supports }\end{array}$ & & $.436^{* * *}$ & $.357 * * *$ \\
\hline $\begin{array}{l}\text { Disconnected from Professor } \\
\text { for at Least One Class }\end{array}$ & & $-.204 * * *$ & $-.126 * * *$ \\
\hline $\begin{array}{l}\text { Professors could improve } \\
\text { course clarity and } \\
\text { communication }\end{array}$ & & & $-.342 * * *$ \\
\hline $\begin{array}{l}\text { Professors could improve } \\
\text { course organization }\end{array}$ & & & $-.381 * * *$ \\
\hline $\begin{array}{l}\text { Professors used many } \\
\text { activities in the online } \\
\text { classroom }\end{array}$ & & & $.327 * * *$ \\
\hline $\bar{R}$ & .115 & .588 & .677 \\
\hline$R^{2}$ & .013 & .346 & .458 \\
\hline Change in $R^{2}$ & & .333 & .112 \\
\hline$F$ & $5.939 *$ & $78.123 * * *$ & $61.889 * * *$ \\
\hline
\end{tabular}

As shown in regression model 3, when controlling for gender, race, the number of course enrolled, and the remote instruction modality, and the availability of reliable internet, $45.8 \%$ of the total variance in student ratings of overall quality of remote instruction was explained by the model, $F=6.889, p<.000$ ). In this model, no control measures were statistically significant, though five elements of the remote learning experience were statistically significant predictors of quality ratings: ratings of the quality of student supports (Academic Advising, Tutoring, Internships, Financial Aid, etc.), ratings of connectedness to instructors in at least one class, the use of many learning activities by instructors, clear course organization by instructors, and clear communication used by instructors.

The responses obtained from the qualitative interviews yielded information that corroborated the data that emerged from the regression analyses. Several themes were identified supporting the Likert-type scale responses from the quantitative analysis. Qualitative data provided a more in-depth understanding as to how students perceived the transition to remote learning and resulted in the themes that follow.

\section{Student Support}

The most significant predictor of a quality remote learning rating was student's rating of the quality of all student supports $(\beta=.307, \mathrm{p}<.000)$. This average rating aggregated individual ratings of: 1$)$ Tutoring, 2) Financial Aid Office, 3) Bursar, 4) IT, 5) Technology Support, 6) Disability Services, 5) international Student Support, 6) Internship/Practicum Placements, and 7) Career Services. All services were used during remote learning by at least 106 students (20\% of all respondents), with the fewest students using International Student Supports $(n=106)$ and Disability Services $(n=108)$. The average rating of the quality 
of all student supports was a more powerful predictor of the rating of the quality of remote learning than any individual student support office.

Six of the 10 students interviewed reported using academic supports during the summer semester. Several students spoke about utilizing online student support service, as evidenced by the student below:

I did use a tutoring service called Tutor Me and it was an amazing tool. If I wasn't able to get anyone through the college itself, you schedule to use that. If I had papers that needed to be rechecked [I could] work with a tutor and they would be able to help me out with the work.

One student shared that additional student supports may have been helpful for remote learning success:

[If] they allowed the students to come into the university to use computers that would have been another alternative that I would have used.

\section{Faculty Support}

Another significant predictor of the quality of remote learning is the connectedness that students felt to their professors $(\beta=-.126, p<.000)$. If a student indicated that they were very disconnected from at least one professor, they were significantly more likely to have lower quality ratings. Student interviews confirmed this, and all students expressed that communication from instructors is particularly important:

Communication is a big, big component [for quality learning], very clear, prompt, communication, and clear expectations.

Another student elaborated on the importance of communication specific to technology:

With remote learning go over [the information]. Show [the technology platform] because a lot of people may have not even navigated the [online] system and have never seen it, or they may have seen it, but they don't understand. The assumption is that [the students] understand the online tools. No. Go over with us on zoom, share your screen, show us what you are discussing, scroll and make sure we can see and understand it.

The interviewees communicated that connectedness could be achieved through timely communication, and clear expectations for the course. The response below is from a student when asked "what makes for a high-quality course during remote learning?"

Ideally the instructor would be a strong prompt resource, so definitely respond within 24 to 48 hours with questions and have very detailed expectations [for the course].

Another student discussed issues in classes with student behaviors such drinking or sitting by the pool. This student elaborated that in one "high quality" course that early communication outlining rules and expectations was important to foster a successful learning environment:

During the first class [we discussed] dos and don'ts with technology. And I thought that was amazing.

\section{Course Organization and Structure}

Students were asked questions about the use of best practices by faculty members in the online classroom, including 1) Using many different learning activities, 2) using Zoom breakout rooms, 3) sharing the instructor's screen, 4) using the Zoom whiteboard, 5) using discussion boards, 6) using other learning management system elements (announcements, posting handouts, etc.), 7) Organizing course material well, 
7) Communicating clearly and consistently. The total number of best practices used by faculty members in the classroom was not a significant predictor of overall quality, but three individual best practices were: Using many activities $(\beta=0.327, \mathrm{p}<.000)$, course organization $(\beta=-.381, \mathrm{p}<.000)$, and clarity in communication $(\beta=-.342, \mathrm{p}<.000)$. The two students below provide further insight into best practices for remote course organization, in response to "what makes for a high-quality course during remote learning?"

Everybody has a chance to talk with the teacher. The professor talks with everybody and [the students] talk to each other all the time. I think the way [the professor] designed the class-it's working. We have the main room or breakout groups, and we go back and forth and discuss things as a large group. [The instructor] usually gives a break, in the three hours. [The professor] usually gave us notes in advance, so those guide us...during the class.

It should be a structured course, so that students know when they are studying, when they are showing up for class... [the instructor should] help them be prepared.

\section{Impact of Technology Preparedness}

Technology Skills

Instructor technology skills and the use of technologies were correlated with student ratings of remote course quality. Students' agreement with the statement 'professors could improve the use of Zoom' saw a moderate significant $(\mathrm{R}=-.317, p<.000)$ negative correlation with ratings of course quality. Additionally, the professors' use of many learning activities was a significant predictor of overall course quality ratings $(\beta=0.327, p<.000)$.

Qualitative findings also demonstrated that technological skills were of concern as much with instructors as with students, as several students reflected:

Even now, I have a professor who, probably half of the class time she spends trying to figure out the Zoom....so I think that that's difficult and frustrating.

If the teachers know the technology, that would make a huge difference. The teacher, she was all the time having computer issues. She didn't know how to break the breakout rooms and it was taking forever. So, to split that, you know, people in small groups...I think that professor, they need to master the tool...

With more emphasis surrounding technology as part of remote learning, students were ready to embrace innovative technological education. Students shared that they did spend time and accessed resources to explore the use of these technologies to help assist with their learning.

What I did the first time Zoom appeared...so this school provides a training, how to use Zoom. How to set up an account and the feature, how to really manage all the features on Zoom. I took that training. So, I already know how zoom function, so I didn't have any problems sharing.

The trainings are the big piece that everybody's supposed to know the students and the teachers. Then after that, you'll be fine. Because you just have to know the platform just to know your stuff and then you'll have no problem. This is the new normal, so I am going to get used to it.

\section{Technology Access}

Access to technology and reliable internet were not significantly related to overall quality ratings of online instruction. This was one important discrepancy between the quantitative and qualitative results, as 
this was a prominent theme in the qualitative interviews. Interview analysis provided a unique description of the student experience regarding technology access. Several students shared that they had issues in accessing distance education technologies during the summer term. Three main themes were identified including Internet connectivity problems, sharing computers, and having a quiet space to study, supported by several quotes, below:

I want to be able to share with my professor clearly without any connection problems... there has been times where...there has been some issues with the platform, and I can't connect.

I have been using a family member's laptop.

Technology was my biggest failure [during the summer term]. It was hard to find the time and space sometimes.

Some people don't have a good signal for the wifi... when it's expensive, some people don't want to spend that much money. Not everybody has the opportunity to pay for the good service.

Students also shared ways of problems solving when dealing with technology access issues, as the student below reflects:

And honestly, I have been using my phone to be able to really listen to the lectures because I know my phone works better than the laptop itself...I use a Chrome book to get my work done. I just use [the computer] to get work done, and then I use my phone to really go into the video conference with the class because the connection doesn't lag.

Although technology was not significant in the quantitative findings, these qualitative insights are interesting to note since technology is foundational to the organization of online education and should be considered a critical component to quality and success.

\section{DISCUSSION}

This article is important to help examine how students from a diverse institution perceived remote learning during the COVID-19 emergency learning transition. Based on our research, five components of a quality distance-learning course were found: quality supports, connectedness to the instructor, clear course organization, the use of many learning activities, and clear communication.

Prior research has shown that support services in education are important (McClary, 2013). This study illuminated the importance of Tutoring and Academic Advising and Success Coaching. In a physical classroom, students can promptly ask questions when unclear on concepts; in contrast, during remote learning, the student and instructor are physically away from each other. Additional student support is beneficial to provide further guidance and assistance; especially in instances where this may not be as accessible in the remote classroom. As a result of social distancing measures, social supports may not be accessible in person, and although students may not be able to drop by an advisor's or tutor's office to chat in person, staff should continue to make sure that they are available to assist students to feel supported wherever they are. In such a scenario, using the technology available to continue to provide these supports is a critical factor.

Consistent with the broad literature, we found that connectedness to the instructor is also paramount to a high-quality learning experience (Creasman, 2012; Dennen, 2014; Richardson et al., 2015; Martin et al., 2018;) Students expressed that communicating clearly and promptly and providing timely feedback were helpful in building instructor connection. Open communication is critical during remote learning so 
that faculty can stay informed to what is working and what is not during the semester, to modify course content as needed. In addition, timely feedback is important to help keep students on track and informed as the course progresses.

Our findings also support the importance of clear course organization to achieve a high-quality remote learning experience. McClary (2013) suggested "a good distance learning course leaves no ambiguity in the students mind regarding how content applies to objectives (p.1)." Advanced course planning on the part of the instructor is important to achieve a structured course format that can be easily maneuvered and communicated, but that planning does not disqualify the need for flexibility, which should be implemented based on feedback during the course progression.

Furthermore, our findings show that the use of many activities within the virtual classroom results in reports of a high-quality learning experience. Online classrooms provide a multitude of communication tools used to facilitate communication between instructors and students and facilitate student-to-student communication (Hew \& Cheung, 2008). Students expressed that the use of discussion boards, breakout rooms, and video instruction in combination were helpful in staying engaged with the material and resulted in feelings of a high-quality course. With the accessibility of these communication tools, students were better able to develop problem-solving and critical thinking skills while maintaining support from peers. However, it should be noted that the effectiveness of different learning activities could vary depending on how they are implemented in the course. Faculty must be well versed in the tools used as well and accessibility concerns for students should be addressed promptly. Training is critical to the understanding and successful implementation of various online tools. For instance, students expressed that Zoom use resulted in problems for some instructors and the time wasted during class took away from the learning experience. Online learning is not new, but with the expansion of this learning methodology including faculty and students previously unfamiliar with this modality, it is important that instructors and students are provided with the knowledge to effectively use online tools to promote successful student learning.

Technology was not found to be a significant predictor of quality remote learning within our quantitative analysis; however, it was a common theme within the qualitative findings. Some students shared that they experienced issues with inconsistent Internet access, had to share a computer, and/or did not consistently have a quiet space and time dedicated to online learning. This confirms that students may encounter unanticipated technological difficulties that impede on their learning experience. Institutional supports should be implemented that may help to reduce unequal learning due to technological issues outside of the students' control.

\section{Limitations}

The study's findings cannot be generalized because they were based on a relatively small number of students from one New England college. However, this study helps to evaluate students' perceptions of their courses during the remote learning period of summer 2020 and can be used to inform teaching practices going forward. More research involving more students from various universities should continue. Further data examining changes that have occurred with remote learning in the Fall and Spring semesters can further inform on lessons learned during COVID-19 and wide scale remote learning. In addition, insights from various stakeholders in education, including instructor and administrator perspectives, will allow for a more comprehensive insight into learning.

\section{CONCLUSION}

The emergency transition to remote learning during COVID-19 presented new challenges in higher education, which leaves room for multiple institutional evaluations. While remote learning became the norm across the globe in 2020, remote learning strategies have not fully been explored at diverse institutions. This study serves as an effort to fill that gap in research. Collecting quantitative data from 529 students, and further supplementing with 10 qualitative interviews this study provides evidence of factors that contribute to a quality remote learning environment. 


\section{REFERENCES}

Allen, I.E., \& Seaman, J. (2014). Grade change: Tracking online education in the United States. Wellesley, MA: Babson Survey Research Group and Quahog Research Group.

Alqurashi, E. (2019). Predicting student satisfaction and perceived learning within online learning environments. Distance Education, 40(1), 133-148. DOI: 10.1080/01587919.2018.1553562

Anderson, M. (2018). About a quarter of rural Americans say access to high-speed Internet is a major problem. Pew Research Center. Retrieved from https://www.pewresearch.org/facttank/2018/09/10/about-a-quarter-of-rural-americans-say-access-to-high-speed-internet-is-amajor-problem/

Boling, E.C., Hough, M., Krinsky, H., Saleem, H., \& Stevens, M. (2012). Cutting the distance in distance education: Perspectives on what promotes positive, online learning experiences. The Internet and Higher Education, 15(2), 118-126.

Dennen, V.P., \& Hao, S. (2014). Intentionally mobile pedagogy: The M-COPE framework for mobile learning in higher education. Technology, Pedagogy and Education, 23(3), 397-419.

Desai, M., Hart, J., \& Richards, T. (2009). E-learning: Paradigm shift in education. Education, 129(2), 327-334.

Dumford, A.D., \& Miller, A.L. (2018). Online learning in higher education: Exploring advantages and disadvantages for engagement. Journal of Computing in Higher Education, 30(3), 452-465.

Federal Communications Commission. (2019). 2019 Broadband deployment report. Retrieved from https://docs.fcc.gov/public/attachments/FCC-19-44A1.pdf

Figlio, D., Rush, M., \& Yin, L. (2010). Is it live or is it internet? Experimental estimates of the effects of online instruction on student learning. doi:10.3386/w16089

Gallien, T., \& Oomen-Early, J. (2008). Personalized versus collective instructor feedback in the online courseroom: Does type of feedback affect student satisfaction, academic performance and perceived connectedness with the instructor? International Journal on E-Learning, 7(3), 463476.

Grajek, S., \& Brooks, C. (2020). How technology can support student success during COVID-19. EduCause Review. Retrieved from https://er.educause.edu/blogs/2020/3/how-technology-cansupport-student-success-during-covid19

Gray, J.A., \& DiLoreto, M. (2016). The effects of student engagement, student satisfaction, and perceived learning in online learning environments. International Journal of Educational Leadership Preparation, 11(1), n1.

Hackman, M.Z., \& Walker, K.B. (1990). Instructional communication in the televised classroom: The effects of system design and teacher immediacy on student learning and satisfaction. Communication Education, 39(3), 196-206.

Hall, J., Roman, C., Jovel-Arias, C., \& Young, C. (2020). Pre-Service teachers examine digital equity amidst schools' COVID-19 responses. Journal of Technology and Teacher Education, 28(2), 435-442.

Hara, N., \& Kling, R. (2001). Student distress in web-based distance education. Educ Q., 3, 68-69.

Harris, C., Straker, L., \& Pollock, C. (2017). A socioeconomic related 'digital divide' exists in how, not if, young people use computers. PloS ONE, 12(3), e0175011. https://doi.org/10.1371/journal.pone.0175011

Hew, K.F., \& Brush, T. (2007). Integrating technology into K-12 teaching and learning: Current knowledge gaps and recommendations for future research. Educational Technology Research and Development, 55, 223-252.

Hew, K.F., \& Cheung, W.S. (2008). Attracting student participation in asynchronous online discussions: A case study of peer facilitation. Computers \& Education, 51(3), 1111-1124.

Hodges, C., Moore, S., Lockee, B., Trust, T., \& Bond, A. (2020). The difference between emergency remote teaching and online learning. Educause Review. Retrieved from 
https://er.educause.edu/articles/2020/3/the-difference-between-emergency-remote-teaching-andonline-learning

Iacobucci, D., Ostrom, A., \& Grayson, K. (1995). Distinguishing service quality and customer satisfaction: The voice of the consumer. Journal of Consumer Psychology, 4(3), 277-303.

Ivankova, N.V., Creswell, J.W., \& Stick, S.L. (2006). Using mixed-methods sequential explanatory design: From theory to practice. Field Methods, 18(1), 3-20. doi:10.1177/1525822X05282260

Johnston, J., Killion, J., \& Oomen, J. (2005). Student satisfaction in the virtual classroom. The Internet Journal of Allied Health Sciences and Practice, 3.

Ke, F., \& Kwak, D. (2013). Online learning across ethnicity and age: A study on learning interaction participation, perception, and learning satisfaction. Computers \& Education, 61, 43-51.

Ku, C.J., Loh, W.L.L., Lin, K.Y., \& John Williams, P. (2020). Development of an instrument for exploring preservice technology teachers' maker-based technological pedagogical content knowledge. British Journal of Educational Technology, e13039.

https://doi.org/10.1111/bjet.13039

Lee, C-Y., \& Witta, L.E. (2001). Online students' perceived self-efficacy: Does it change? Paper presented at the National Convention of the Association for Educational Communications, Atlanta, GA.

Lee, J. (2014). An exploratory study of effective online learning: Assessing satisfaction levels of graduate students of mathematics education associated with human and design factors of an online course. International Review of Research in Open and Distributed Learning, 15(1), 111-132.

Letcher, D.W., \& Neves, J.S. (2010). Determinants of undergraduate business student satisfaction. Research in Higher Education Journal, 6, 1.

Martin, F., Wang, C., \& Sadaf, A. (2018). Student perception of helpfulness of facilitation strategies that enhance instructor presence, connectedness, engagement and learning in online courses. The Internet and Higher Education, 37, 52-65.

McClary, J. (2013). Factors in high quality distance learning courses. Online Journal of Distance Learning Administration, 16(2), 230-256.

Milman, N.B., Posey, L., Pintz, C., Wright, K., \& Zhou, P. (2015). Online master's students' perceptions of institutional supports and resources: Initial survey results. Online Learning, 19(4).

National Telecommunications and Information Administration. (2016). Digitally unconnected in the U.S.: Who's not online and why? Washington, DC: Author.

Parasuraman, A., Zeithaml, V.A., \& Berry, L.L. (1985). A conceptual model of service quality and its implications for future research. Journal of Marketing, 49(4), 41-50.

Peterson, C., \& Bond, N. (2004). Online compared to face-to-face teacher preparation for learning standards-based planning skills. Journal of Research on Technology in Education, 36, 345-360. 10.1080/15391523.2004.10782419

Rettig, M. (2013). Online postings of teacher education candidates completing student teaching: What do they talk about? Linking Research \& Practice to Improve Learning, 57(4), 40-45.

Richardson, J.C., Koehler, A.A., Besser, E.D., Caskurlu, S., Lim, J., \& Mueller, C.M. (2015). Conceptualizing and investigating instructor presence in online learning environments. The International Review of Research in Open and Distributed Learning, 16(3).

Seaman, J.E., Allen, I.E., \& Seaman, J. (2018). Grade increase: Tracking distance education in the United States. Wellesley, MA: The Babson Survey Research Group.

Smart, K.L., \& Cappel, J.J. (2006). Students' perceptions of online learning: A comparative study. Journal of Information Technology Education: Research, 5(1), 201-219.

Stokes, S.P. (2003). Temperament, learning styles, and demographic predictors of college student satisfaction in a digital learning environment. Paper presented at the annual meeting of the MidSouth Educational Research Association, Biloxi, MS.

Sun, P-C., Tsai, R.J., Finger, G., Chen, Y-Y., \& Yeh, D. (2008). What drives a successful e-learning? An empirical investigation of the critical factors influencing learner satisfaction. Computers \& Education, 50(4), 1183-1202. 
World Economic Forum. (2020). The COVID-19 pandemic has changed education forever. This is how. Retrieved from https://www.weforum.org/agenda/2020/04/coronavirus-education-globalcovid19-online-digital-learning

Xu, D., \& Jaggars, S. (2013). Adaptability to online learning: Differences across types of students and academic subject areas. Retrieved from http://academiccommons.columbia.edu/catalog/ac:157286 